\title{
Serviço aeromédico em aeronaves de asas rotativas: realidade e perspectiva
}

\section{profissional}

\author{
Helicopter aeromedical service: reality and professional perspective \\ Servicio aeromédico de helicópteros: realidad y perspectiva profesional
}

Recebido: 04/09/2021 | Revisado: 10/09/2021 | Aceito: 13/09/2021 | Publicado: 15/09/2021

Keyla Cristiane do Nascimento

ORCID: https://orcid.org/0000-0003-4157-2809

Universidade Federal de Santa Catarina, Brasil E-mail: keyla.n@ufsc.br

André Ricardo Moreira

ORCID: https://orcid.org/0000-0002-9888-5120 Secretaria do Estado da Saúde de Santa Catarina, Brasil E-mail: flightnurseandre@gmail.com

Euseli de Assis Batista

ORCID: https://orcid.org/0000-0002-0107-3565 Secretaria do Estado da Saúde de Santa Catarina, Brasil E-mail: euselibatista@gmail.com

Bárbara Duarte Dutra

ORCID: https://orcid.org/0000-0001-6971-6283 Secretaria do Estado da Saúde de Santa Catarina, Brasil E-mail: barbaraddutra@gmail.com

Alexandre dos Santos Caminha Júnior

ORCID: https://orcid.org/0000-0003-3217-9896 Universidade Federal de Santa Catarina, Brasil E-mail: alexandrecaminhajr@gmail.com

\begin{abstract}
Resumo
Objetivo: compreender a realidade laboral e perspectivas dos profissionais que integram a equipe de atendimento aeromédico de Santa Catarina. Metodologia: Estudo exploratório, descritivo, com enfoque qualitativo. Foram realizadas 17 entrevistas com profissionais que integram o serviço aeromédico de helicópteros em Santa Catarina (médicos, enfermeiros, tripulantes operacionais e pilotos de aeronave). Utilizou-se entrevista semiestruturada, transcritas e analisadas por meio de análise de conteúdo. Resultados: da análise de conteúdo temática emergiram quatro categorias: atitude e conhecimento como necessidades de trabalho; responsabilidades e desafios profissionais; atributos para o serviço aeromédico e circunstâncias expressivas na perspectiva profissional do atendimento aeromédico. As categorias refletem questões que estiveram presentes nos discursos, evidenciando a importância do conhecimento e da aptidão técnica para a estabilização do paciente de emergência na atividade aeromédica. Os desafios profissionais foram representados por imprevisibilidade de acionamentos, atendimento com locais de difícil acesso e condições climáticas desfavoráveis. Conclusão: o estudo possibilitou compreender a realidade e percepção que os profissionais do serviço aeromédico possuem a respeito do trabalho que realizam. Enquanto modalidade de atendimento de emergências, exige múltiplas competências dos profissionais envolvidos, demonstrando a importância da capacidade técnica e cognitiva para a estabilização clínica do paciente, ancorado em conhecimento sobre fisiologia de voo, segurança de voo e navegabilidade; aliado a uma resiliência física. Percebe-se a predominância de um discurso hegemônico, com destaque para o trabalho em equipe, comunicação e confiança interprofissional.

Palavras-chave: Resgate aéreo; Serviços médicos de emergência; Assistência pré-hospitalar; Equipe de assistência ao paciente; Fluxo de trabalho.

Abstract

Objective: to understand the work reality and perspectives of professionals who are part of the aeromedical care team in Santa Catarina. Methodology: Exploratory, descriptive study with a qualitative focus. Seventeen interviews were conducted with professionals who are part of the helicopter aeromedical service in Santa Catarina (doctors, nurses, operational crew and aircraft pilots). Semi-structured interviews were used, transcribed, and analyzed through content analysis. Results: from the thematic content analysis, four categories emerged: attitude and knowledge as work needs; professional responsibilities and challenges; attributes for aeromedical service and expressive circumstances from the professional perspective of aeromedical care. The categories reflect issues that were present in the speeches, they show the importance of knowledge and technical aptitude for the stabilization of emergency patients in aeromedical activity. The professional challenges were represented by the unpredictability of activations, service in places with
\end{abstract}


difficult access and unfavorable weather conditions. Conclusion: the study made it possible to understand the reality and perception that aeromedical service professionals have about the work they perform. As an emergency care modality, requires multiple skills of the professionals involved, demonstrating the importance of technical and cognitive capacity for the patient's clinical stabilization, anchored in knowledge of flight physiology, flight safety and navigability; combined with physical resilience. It is noticed the predominance of a hegemonic discourse, with emphasis on teamwork, communication and interprofessional trust.

Keywords: Air ambulances; Emergency medical services; Prehospital care; Patient care team; Workflow.

\begin{abstract}
Resumen
Objetivo: comprender la realidad laboral y las perspectivas de los profesionales que forman parte del equipo de atención aeromédica en Santa Catarina. Metodología: Estudio exploratorio descriptivo con enfoque cualitativo. Se realizaron diecisiete entrevistas a profesionales que forman parte del servicio aeromédico de helicópteros en Santa Catarina (médicos, enfermeras, tripulación operativa y pilotos de aeronaves). Se utilizaron, transcribieron y analizaron entrevistas semiestructuradas mediante análisis de contenido. Resultados: del análisis de contenido temático surgieron cuatro categorías: actitud y conocimiento como necesidades laborales; responsabilidades y desafíos profesionales; Atributos para el servicio aeromédico y circunstancias expresivas desde la perspectiva profesional del servicio aeromédico. Las categorías reflejan cuestiones que estuvieron presentes en los discursos, destacando la importancia del conocimiento y la aptitud técnica para la estabilización de los pacientes de emergencia en la actividad aeromédica. Los desafíos profesionales estuvieron representados por la imprevisibilidad de las activaciones, el servicio en lugares de difícil acceso y condiciones climáticas desfavorables. Conclusión: el estudio permitió conocer la realidad y percepción que tienen los profesionales del servicio aeromédico sobre el trabajo que realizan. Como modalidad de atención de emergencia, requiere múltiples habilidades de los profesionales involucrados, demostrando la importancia de la capacidad técnica y cognitiva para la estabilización clínica del paciente, anclado en el conocimiento de la fisiología del vuelo, la seguridad del vuelo y navegabilidad; combinado con resiliencia física. Se advierte el predominio de un discurso hegemónico, con énfasis en el trabajo en equipo, la comunicación y la confianza interprofesional.
\end{abstract}

Palabras clave: Ambulancias aéreas; Servicios médicos de urgencia; Atención prehospitalaria; Grupo de atención al paciente; Flujo de trabajo.

\title{
1. Introdução
}

O Serviço aeromédico é uma modalidade do atendimento pré-hospitalar móvel, dotado de suporte avançado de vida. Consiste em uma assistência de pacientes por via aérea, em aeronaves de asa rotativa (helicóptero) ou asa fixa (avião) e possui duas modalidades de atendimento de saúde: primário (pedido de atendimento de um cidadão) e secundário (solicitação de um serviço de saúde).

Realiza atendimento primário, na cena do evento, quando a solicitação é proveniente de um cidadão, e atendimento secundário, transporte inter-hospitalar, quando a solicitação parte de um serviço de saúde, no qual o paciente já tenha recebido o primeiro atendimento necessário à estabilização do quadro de urgência apresentado, mas necessita de remoção aérea para ser conduzido ao serviço de maior complexidade para continuidade do tratamento (Blera \& Ribas, 2018).

O serviço integra a Política Brasileira de Atenção às Urgências e Emergências. Para o pleno funcionamento do serviço aeromédico, este deve estar integrado ao sistema de atendimento pré-hospitalar móvel e à Central de Regulação Médica de Urgências da região (Ministério da Saúde, 2003).

O Batalhão de Operação Aérea de Santa Catarina, lócus do estudo, por meio de aeronaves de asas-rotativas (helicóptero) desempenha papel fundamental nas ações de resgate, atendimento e transferências inter-hospitalares, com suporte avançado a vida (Santa Catarina, 2010). Sua equipe é composta por médico de voo, enfermeiro de voo, piloto e tripulante operacional, com conhecimentos teóricos e habilidades práticas, tanto no atendimento ao paciente crítico quanto nos conhecimentos de fisiologia aeroespacial.

A utilização do recurso aeromédico tem aumentado significativamente, tendo em vista os benefícios alcançados pela sua rapidez no deslocamento de grandes percursos em um curto intervalo de tempo. Concomitante a isso, alia-se, muitas vezes, as dificuldades do atendimento terrestre devido às condições de trânsito nos grandes centros e a possibilidade de atingir regiões 
de difícil acesso (Raduenz et al., 2020). A agilidade para que um paciente crítico receba seu tratamento definitivo influência na sua sobrevida, bem como na diminuição de sequelas (Schweitzer et al., 2017).

Entende-se que o serviço aeromédico possui algumas particularidades e estas podem tornar-se hostis para todos os profissionais da equipe. O processo de trabalho é permeado por situações de urgência e emergência no aerotransporte de pacientes conscientes e inconscientes, graves ou estáveis e de qualquer idade. As dificuldades encontradas no dia a dia vão desde a condição do paciente às alterações ambientais do voo, ou seja, as que podem ser controladas e as que fogem ao controle. Apesar de todo planejamento e organização, o ambiente está permeado de situações adversas e complicações a todo instante (Dias, Ferreira \& Carvalho, 2017).

Nesse sentido, torna-se oportuno conhecer o trabalho dos profissionais que atuam no serviço aeromédico e promover uma reflexão sobre suas perspectivas profissionais. O estudo teve como objetivo compreender a realidade laboral e perspectivas dos profissionais que integram a equipe de atendimento aeromédico de Santa Catarina.

\section{Metodologia}

Estudo exploratório-descritivo com enfoque qualitativo, cujo propósito foi o de explorar e descrever as atividades dos profissionais que atuam no serviço aeromédico em seu ambiente natural de trabalho para melhor análise de sua realidade. Realizado no Batalhão de Operações Aéreas de Santa Catarina, que funciona ininterruptamente entre o nascer e o pôr do sol, e utiliza aeronave de asa rotativa (Esquilo B-02) para o atendimento de pacientes.

A equipe do serviço aeromédico de asa rotativa é composta por 35 profissionais, sendo que 15 profissionais integram a equipe de saúde (médicos e enfermeiros) e 20 profissionais pertencem ao quadro de segurança pública (pilotos e tripulantes operacionais).

A amostra intencional respeitou os seguintes critérios de inclusão: ser profissional do Batalhão de Operações Aéreas médico de voo, enfermeiro de voo, piloto ou tripulante operacional, com o tempo mínimo de seis meses de experiência. Considera-se este tempo minimamente necessário para a adaptação do profissional às rotinas do setor e à equipe de trabalho, podendo, desse modo, contribuir de forma mais efetiva com a investigação. Como critério de exclusão estavam ausência decorrente de férias, treinamento ou licença de qualquer natureza no período de coleta de dados. Os profissionais foram pessoalmente convidados a participar do estudo pelo pesquisador principal e o espaço físico utilizado para a realização das entrevistas foram ambientes sem ruídos e sem a presença de outros indivíduos. A participação dos entrevistados foi voluntária, sem ônus e foram resguardadas suas identidades e as informações que pudessem identificá-los individualmente.

Para manter o rigor do estudo foram utilizados os critérios estabelecidos por Tong, Sainsbury e Craig (2007) no Consolidated Criteria for Reporting Qualitative Research (COREQ). As entrevistas foram conduzidas pela pesquisadora principal e por uma acadêmica de enfermagem do último ano de graduação da Universidade Federal de Santa Catarina, no período entre setembro e novembro de 2018, mediante roteiro próprio, com questionamentos relacionados ao cotidiano de trabalho, estrutura organizacional, relação entre os membros da equipe e perspectivas profissionais.

A técnica de pesquisa utilizada para coleta de dados foi a entrevista semiestruturada. As entrevistas foram realizadas individualmente, gravadas em dispositivo eletrônico de áudio mediante autorização prévia dos sujeitos e posteriormente transcritas na integra no programa de digitação Microsoft Word®. O critério utilizado para o término das entrevistas foi o da saturação de dados em que o processo foi interrompido quando observado a repetição do conteúdo nos relatos dos participantes (Fontanella et al., 2011). 
O tempo das entrevistas variou de $11 \mathrm{~min} 28 \mathrm{~s}$ a $21 \mathrm{~min} 08 \mathrm{~s}$, com uma média de $13 \min 10 \mathrm{~s}$. Vale ressaltar que foram realizadas duas entrevistas-piloto com profissionais da instituição com vistas ao aprimoramento dos instrumentos e posterior início da pesquisa. Estas entrevistas não foram contempladas para análise.

Para a análise das entrevistas, utilizou-se a técnica de análise de conteúdo de Laurence Bardin (2011), pautada em três etapas: pré-análise, exploração do material e tratamento dos resultados obtidos e interpretação.

Por meio da categorização, foram iniciadas as interpretações, objetivando compreender os significados e percepções do contexto estudado. Para a apresentação dos trechos das entrevistas nos resultados do estudo, e como forma de manter o anonimato, os entrevistados foram designados pela letra inicial da categoria profissional, ou seja, (E) Enfermagem; (M) Medicina (P) Piloto; e (T) Tripulante Operacional, numerados de acordo com a ordem da coleta de dados.

A pesquisa seguiu a Resolução no 466/2012 do Conselho Nacional de Saúde. O projeto foi autorizado pela instituição e aprovado por Comitê de Ética em Pesquisa com Seres Humanos, sob parecer nº 1.691.870.

\section{Resultados}

Participaram do estudo 17 profissionais que atuam no serviço aeromédico, sendo três médicos (18\%), quatro tripulantes operacionais (24\%), cinco enfermeiros (29\%) e cinco pilotos de aeronave (29\%). Em relação à idade, a média foi de 33 anos, e o sexo masculino foi o mais evidenciado, correspondendo a $13(76 \%)$ participantes.

Da análise de conteúdo temática emergiram quatro categorias: Atitude e conhecimento como necessidades de trabalho; Responsabilidades e desafios profissionais; Atributos para o serviço aeromédico e Circunstâncias expressivas na perspectiva profissional do atendimento aeromédico. As categorias refletem questões que estiveram presentes nos discursos, demonstrando o entendimento dos próprios profissionais.

\section{Atitude e conhecimento como necessidades de trabalho}

A categoria intitulada atitude e conhecimento como necessidades de trabalho, emergiu a partir dos questionamentos relacionados ao cotidiano de trabalho e estrutura organizacional. O conteúdo das respostas evidenciou a importância da capacidade técnica e cognitiva exigida para o serviço aeromédico.

Profissionais de saúde salientam a importância do conhecimento para a estabilização do quadro clínico do paciente, devendo estar familiarizados com os principais protocolos de atendimento clínicos e de trauma, para um reconhecimento rápido de instabilidade fisiológica. Relatam ainda, que para manter o serviço com qualidade os profissionais devem se atualizar constantemente no que concerne a atividade aeromédica: fisiologia e segurança de voo, navegabilidade, preparo físico, dentre outros.

O aeromédico é a parte que você desempenha todo o know how do teu conhecimento da graduação em relação ao paciente grave. (E1)

[...] é um desafio diário de fazer frente a ocorrências que normalmente você, quando sai da base, tem um histórico inicial da situação, mas não tem certeza da gravidade. Então, conhecimento é fundamental. (M2)

Te exige um alinhamento de raciocínio e condutas de padrões de trabalho (M3)

[...] além do conhecimento técnico de sua função, precisa ser um conhecedor da enfermagem espacial e aeromédica, das questões de aviação, segurança de voo, navegabilidade. A atualização deve ser constante e esse é o nosso diferencial no serviço aeromédico (E4) 
Para a equipe de tripulantes e pilotos, inteirar-se sobre pontos de referência e locais para pouso, além de analisar a viabilidade ou não do voo, são essenciais no serviço aeromédico, conforme evidenciado nos discursos:

Para a segurança do voo a gente tem que conhecer o local de pouso, algum ponto de referência ou alguém que conhece o lugar e as coordenadas (T4).

É uma imensa responsabilidade levar a equipe para atender com segurança e trazer a equipe e a vítima em segurança, então esse conhecimento é fundamental. Exige que a gente domine desde a conferência da aeronave, as condições meteorológicas até emergências que podem vir a ocorrer com a aeronave (P2)

Os participantes do estudo destacam ainda as atitudes pessoais, que se configuram como contribuições dos integrantes para um bom desempenho durante o serviço, dando ênfase para a importância do profissional ter bom condicionamento físico, além de estar bem alimentado e descansados, como observado nos seguintes depoimentos:

[...] porque além da capacidade técnica, capacidade cognitiva, a gente tem que se preocupar com a parte do condicionamento físico. Muitas ocorrências são em locais de difícil acesso e o helicóptero nem sempre consegue pousar ao lado da ocorrência (M1).

O trabalho sempre começa um dia antes. A gente tem que vir bem descansado para manter o nível de atenção elevado (T3).

Destaca-se que as atividades realizadas neste universo requerem equilíbrio emocional, capacidade física e mental para a atividade, além de conhecimento voltado ao atendimento de urgência e emergência na atividade aeromédica. Assim, podemos observar o quão importante é para o serviço aeromédico, haver uma interação de conhecimentos entre os profissionais aliado a uma resiliência física, a fim de se oferecer ao paciente atendido, uma assistência de qualidade.

\section{Responsabilidades e desafios profissionais}

No que se refere, a categoria responsabilidades e desafios profissionais, construída com base no questionamento sobre a percepção do dia a dia de trabalho no atendimento aeromédico, retratam a possibilidade de trabalhar em um ambiente desafiador, pois os cenários de atendimentos nunca se repetem. Tal entendimento fica evidenciado nos discursos:

Temos profissionais que são apaixonados pelo serviço aéreo e temos profissionais que gostam do desafio (M3).

Você acaba adquirindo destreza, rapidez e conhecimento que no hospital, na função de enfermeiro, você delegaria algumas coisas e outras você faria com o auxílio de três ou quatro pessoas. Então eu vejo isso como um diferencial muito grande (E5).

[...] a complexidade do atendimento nos diversos cenários faz com que você acabe se modelando a ser um profissional mais assertivo e mais técnico que procura fazer mais na cientificidade, na operacionalização (E1).

O dia de trabalho é caracterizado pela imprevisibilidade de acionamentos e atendimentos, porém, há uma rotina de conferência de materiais e equipamentos. Citam os procedimentos diários de briefing para conferência da aeronave e dos materiais para os atendimentos. 
Uma ocorrência nunca é igual a outra. São várias situações diferentes e tem uma tendência de ter nível de complexidade maior com os pacientes que a gente atende (M2).

Depois da conferência inicial dos equipamentos e da aeronave é feito um briefing, que é a verificação de como estão todos da tripulação, se o pessoal está bem e descansado. Levantar as defesas, para eventual perigo. (P1)

Como a gente trabalha com muitas áreas precisa fazer várias conferências, desde material de resgate, material de salvamento de altura, desencarceramento de veículo, entre outros. Dependendo do tipo da ocorrência levamos um tipo de material em específico (T2).

Os profissionais de saúde são responsáveis pelo checklist das mochilas com materiais para atendimento, mantendo a organização dos equipamentos, medicamentos e materiais e estabelecendo sua disposição na aeronave a fim de realizar uma assistência segura. São também responsáveis pelo registro de atendimento do paciente. Os profissionais de segurança pública ficam encarregados dos protocolos diários de conferência das condições da aeronave e relatórios de voo. A todos os profissionais compete a participação no briefing matinal e debriefing após ocorrência.

\section{Atributos para o serviço aeromédico}

Os atributos para o serviço aeromédico definiram outra categoria na análise dos dados, onde o trabalho em equipe, a comunicação e a confiança interprofissional foram consideradas essenciais. Os participantes consideram que o trabalho em equipe ocupa lugar de destaque nesse contexto, pois existe uma interdependência para que o trabalho seja realizado de forma harmoniosa. Consideram relevante a participação ativa de todos os integrantes da equipe multiprofissional durante o atendimento ao paciente crítico (que se encontra em risco iminente de perder a vida ou a função de órgão/sistema do corpo humano e requeiram assistência imediata), como se observa nos depoimentos a seguir:

No aeromédico existe uma ação conjunta. A gente vai com uma determinada finalidade. O trabalho em equipe é o xis da questão para o atendimento funcionar. Se não tiver trabalho em equipe, o serviço não anda. Se um depende do outro, tem que ter cooperação. Uma equipe funcionando é harmonia. Um contribui para o trabalho do outro, apesar de cada um possa ter função diferente (E3).

Tanto eu preciso deles como eles precisam de mim, e nós precisamos também não só de quem está ali na hora da ocorrência, mas também do mecânico de aeronave, da equipe de limpeza, da central de regulação. Somos todos uma equipe e não fazemos nada sozinhos (E2).

Os participantes do estudo destacam ainda a importância da comunicação, pois é preciso saber lidar com situações complexas na realização das atividades. Por isto, é preciso ser capaz de se comunicar através de palavras e de gestos padronizados. A comunicação se aperfeiçoa e prospera com a experiência da prática, com o fortalecimento dos vínculos de confiança, com as trocas de conhecimentos e, especialmente, no viver juntos, seja em espaços formais ou informais. Com isso, os profissionais conseguem otimizar e sincronizar suas ações.

Independente da situação que se apresenta, nossa equipe já sabe o que tem que ser feito. Cada um desempenha o seu papel utilizando o seu conhecimento teórico [...] e desempenha sua prática (P4). 
[...] muitas vezes um olhar de um para outro, já sabe o que é preciso fazer. Aqui há muitos tipos de ocorrência complexas, com múltiplas vítimas, em locais de difícil acesso. Então, em um olhar a gente já sabe qual vai ser a conduta de cada um na ocorrência (T1).

Outro aspecto levantado pelos participantes do estudo é a confiança interprofissional que os indivíduos estabelecem no coletivo de trabalho. A convivência cotidiana e a experiência obtida em suas relações de trabalho ao longo do tempo, contribuem significativamente na consolidação desta confiança.

Aqui o trabalho é em equipe, todo mundo já se conhece, já sabe o que precisa fazer [...] A ocorrência flui sem precisar falar. É bem sincronizado porque nós nos complementamos (E5).

O cotidiano de trabalho revela um compartilhamento das ações e dos saberes, na prática diária de suas atividades. Atuar no serviço aeromédico traz responsabilidade, habilidades específicas e alto grau de conhecimento, porém exige ainda, um alinhamento do trabalho em equipe, comunicação como um componente essencial da assistência e a confiança nas condutas e na troca de conhecimentos. Tais atributos, refletem o engajamento e a solidez existente na equipe.

\section{Circunstâncias expressivas na perspectiva profissional do atendimento aeromédico}

A categoria circunstâncias expressivas foi construída a partir da análise de respostas às questões sobre as perspectivas profissionais do atendimento aeromédico. Os participantes destacam que por critérios operacionais, nem todos os acionamentos ocorrem pela gravidade do paciente, mas pelo fato de haver locais de difícil acesso, indisponibilidade da ambulância, alcance rápido ou exigências especiais para o atendimento.

Existem demandas distintas para nós. Já realizamos ocorrências que não precisavam de um atendimento com suporte avançado, mas que precisavam de um atendimento rápido por causa da localidade de difícil acesso (P3).

A prioridade de atendimento das situações graves, onde há risco de morte iminente do paciente, deve ser baseada na avaliação dos benefícios potenciais, ponderados contra os riscos potenciais, como condições meteorológicas, por exemplo. A razão básica para o atendimento do paciente crítico com emprego do helicóptero é a necessidade de cuidados adicionais (tecnologia e/ou especialistas), não disponíveis no local onde o paciente se encontra. Nesses casos, devido à gravidade do paciente, são necessários um tempo maior para a realização do atendimento e procedimentos.

O helicóptero deve ser empenhado em situações graves onde existe risco de morte da vítima, mas nem sempre isso é possível. Quando não há visibilidade para voo, não há segurança para a equipe e consequentemente não podemos ser acionados (M1).

Os participantes afirmam que o atendimento aeromédico também apresenta desvantagens. Além das limitações às condições climáticas e noturnas, esse tipo de veículo apresenta espaço interno reduzido, vibrações e ruídos da própria aeronave, cinetose (enjoo de movimento) e custo elevado de operação, conforme relatos:

Apesar da agilidade para chegar no local do atendimento, o helicóptero tem um espaço muito reduzido para o transporte do paciente. A equipe vem ajoelhada dentro do helicóptero e pacientes muito altos precisam encolher a perna, se não for possível, voamos com a porta da aeronave aberta (T3).

Quando você está no voo, existe o desafio de lidar com os ruídos dentro da cabine, existe o desafio de lidar com a cinetose nesse tipo de atendimento (E1). 
Percebe-se a partir dos relatos dos profissionais que o serviço aeromédico em aeronaves de asas rotativas é complexo e comporta fatores que vão influenciar diretamente no emprego da equipe para diferentes tipos de atendimento, por isso, vale considerar as mais variadas circunstâncias que integra.

\section{Discussão}

A primeira categoria traz aspectos acerca da importância da capacidade técnica e cognitiva exigida para o serviço aeromédico. Para tanto, os profissionais de saúde devem estar preparados para reconhecer, por meio da avaliação inicial, os sinais de gravidade (Oliveira, Brandão, Reis \& Giustina, 2017). A impressão inicial do paciente em situação de urgência forma uma representação mental que possibilita o reconhecimento rápido de instabilidade fisiológica. As funções vitais devem ser sustentadas até que o tratamento definitivo apropriado seja instituído (Alfes, 2020).

O serviço aeromédico exige dos profissionais envolvidos no atendimento, conhecimento sobre a fisiologia do voo e sobre as suas possíveis repercussões no quadro do paciente, sendo esse conhecimento fundamental para atuação no ambiente aeroespacial. Ainda, são necessárias noções de aeronáutica como terminologia, segurança no interior e em torno das aeronaves e embarque e desembarque de pacientes que devem seguir as determinações do Regulamento Brasileiro da Aviação Civil ((Blera \& Ribas, 2018; Pereira, Galdino, Barreto \& Martins, 2021).

No Brasil, a Portaria 2048/2002 define, entre outras atividades, requisitos básicos para aeronaves e qualificações de tripulação de saúde (Ministério da Saúde, 2002). O Regulamento Brasileiro da Aviação Civil - RBAC 90/2019, determina a obrigatoriedade da realização de treinamentos específicos de ambientação para profissionais de saúde com atribuições específicas a bordo, para a realização de operações aeromédicas, resgates e salvamentos, definidos como operador de suporte médico (ANAC, 2019). Ainda, a Resolução 660/21 do Conselho Federal de Enfermagem (COFEN, 2021) normatiza a especialidade de enfermagem aeroespacial para os enfermeiros de voo em exercício e define como critério a realização de especialização lato sensu em Enfermagem Aeroespacial para os enfermeiros que venham iniciar a atividade aeroespacial.

Assim, os profissionais que participam do atendimento aeromédico, devem receber treinamento adequado acerca de situações clínicas e sua relação com a fisiologia em uma situação de voo. Devem estar munidos de conhecimentos acerca de protocolos de atendimento específicos para cada tipo de situação emergencial (Oliveira et al., 2017), além de realizar avaliações rápidas, definir prioridades, tomar decisões assertivas e intervir na saúde do paciente crítico de maneira adequada.

Estudo realizado na Austrália com enfermeiras de voo, apontam que o conhecimento técnico específico auxilia na tomada de decisão. Entretanto, habilidades não técnicas de resiliência física e mental, adaptabilidade e flexibilidade receberam destaque dentro da função de resgate aeromédico (Martin \& Kumar, 2020), dados esses análogos aos do presente estudo.

A segunda categoria apresenta aspectos relacionados aos desafios profissionais. Pode-se identificar pelos depoimentos, que apesar da disponibilidade de recursos tecnológicos de última geração no serviço aeromédico, torna-se cada vez maior a exigência e a responsabilidade entre os profissionais da saúde que prestam o atendimento (Dias et al., 2017). Desse modo, é preciso que os profissionais demonstrem segurança, por mais que o ambiente seja adverso. Tendo em vista que algumas situações se tornam complexas, com equipe reduzida, espaço restrito e com paciente crítico.

Neste sentido, adaptar-se ao ambiente de atendimento aeromédico é desafiador e complexo para os profissionais, com muitas variáveis que vão além do gerenciamento do estado crítico do paciente (Alfes, 2020). Dado o ambiente incerto e imprevisível, uma forte cultura de segurança deve ser estabelecida em toda equipe, estendendo-se dos pilotos, tripulantes operacionais e profissionais de saúde as equipes de solo (Alfes, 2020; Santos, Guedes \& Aguiar, 2014). Além disso, todos os membros do serviço aeromédico são responsáveis por garantir a segurança da equipe e do paciente, até sua estabilização e aerotransporte para o tratamento definitivo. 
A preocupação com a segurança do paciente e da equipe no atendimento e aerotransporte inicia-se na fase pré-voo, onde médico e enfermeiro realizam a checagem das bolsas de resgate, conferência, previsão e provisão de insumos e medicamentos, e verificação do funcionamento dos aparelhos tais como: monitor cardíaco, desfibrilador, aspirador e ventilador mecânico portátil, prancha de transporte e cilindro de oxigênio (Santos et al., 2014). A divisão das tarefas e os sistemas de estabelecimento de rotinas para conferência de materiais e equipamentos estão relacionados à segurança operacional, desenvolvidos e difundidos com vistas à elevação dos índices de segurança na aviação (Raduenz et al., 2020; Dias et al., 2010).

Estudos sobre a atuação do serviço aeromédico no Brasil enfatizam a importância dos profissionais de saúde na previsão e provisão de materiais e equipamentos na gestão de insumos e materiais nos serviços de saúde (Blera \& Ribas, 2018; Raduenz et al., 2020; Santos et al., 2014). A responsabilidade pela checagem das bolsas de resgate, conferência de materiais e insumos e verificação da funcionalidade dos equipamentos deve ser partilhada com a equipe de bordo, minimizando possíveis erros e aumentando a segurança para o paciente (Santos et al., 2014; Dias \& Penna, 2014). A segurança do paciente que se inicia no pré-voo, por meio do planejamento adequado da assistência em conjunto com a equipe multidisciplinar, tem sua continuidade no voo propriamente dito.

Influenciados diretamente pelas normas da aviação civil, no contexto da cultura organizacional do BOA, realiza-se, como padrão, o briefing diário. As orientações para o trabalho seguem um roteiro formal, através de um fluxo lógico que favorece a execução das tarefas: conferencia da aeronave, de materiais e equipamentos, condições meteorológicas, entre outras. São realizados e enfatizados os briefings de forma que todas as atividades sejam precedidas de uma comunicação que não apenas informa e esclarece, mas cria condições para que falhas e problemas sejam prevenidos (Comando da Aeronáutica [COMAER], 2012).

Realizam, como opção, o debriefing da missão recém realizada, dando a todos os envolvidos a oportunidade de fazer uso da palavra e comentar suas impressões sobre o atendimento, os acertos e erros, o que poderia ter sido feito de diferente ou de maneira mais segura, dentre outras opiniões (ANAC, 2019; COMAER, 2012).

Com relação aos atributos para o serviço aeromédico, terceira categoria, o trabalho em equipe, a comunicação e a confiança interprofissional receberam destaque. No cenário do atendimento aeromédico, os pacientes críticos necessitam de uma assistência rápida e eficaz. Assim, esse serviço requer a atuação conjunta e sincronizada entre os profissionais, para que o trabalho aconteça de forma efetiva. Portanto, o trabalho em equipe se torna parte integrante do cuidado na assistência ao paciente crítico, facilitando ainda, a coesão e o fortalecimento do vínculo entre os profissionais (Dias et al., 2017).

Estudo brasileiro sobre o processo de trabalho no transporte aeromédico revela que o trabalho em equipe é um fator facilitador para o labor, proporcionando confiança na equipe, dados esses que são análogos aos do presente estudo (Pereira et al., 2021). A existência de confiança e cooperação entre os membros da equipe e a liberdade para expor opiniões para os membros da equipe, influenciam diretamente no processo de trabalho e no desenrolar do atendimento (Alfes, 2020).

No serviço aeromédico, o fortalecimento da confiança mútua e a parceria, tornam-se parte integrante do trabalho em equipe e pode ser compreendido como um querer profissional (Dias et al., 2017). Assim, a proximidade e a relação de ajuda tornam o trabalho agradável e facilitam o desempenho das atividades. No entanto, trabalhar em equipe, é um processo que exige tempo e não significa ter a mesma visão, as opiniões podem ser divergentes, mas é preciso encarar e dialogar com o colega, sem restrições.

As falas dos entrevistados destacam ainda, a comunicação como uma habilidade essencial para o serviço aeromédico. Aliada à tomada de decisão em prol do cuidado ao paciente, a comunicação torna-se fundamental e possibilita constante integração em equipe (Costa et al., 2013). A comunicação efetiva entre os membros da equipe tanto na parte terrestre quanto na comunicação de cabine precisa acontecer de maneira organizada e objetiva, com a finalidade de atender todo o processo do 
atendimento aeromédico com qualidade (Dias et al., 2017). Portanto, a interação, confiança e comunicação entre os profissionais, tornam-se a base do processo de trabalho em equipe.

No tocante as circunstâncias expressivas no atendimento aeromédico, quarta categoria, o aerotransporte do paciente crítico terá sucesso quando for realizado uma criteriosa avaliação da situação, observando-se os critérios operacionais de acionamentos. Assim, o processo decisório na avaliação dos benefícios deve ser ponderado com os riscos potenciais (Bonin et al., 2016) como condições meteorológicas desfavoráveis, pousos em áreas restritas, locais de dimensões reduzidas e horário das operações (limitadas ao pôr do sol para aeronaves que não voam por instrumentos).

Dentre os aspectos facilitadores e benéficos verbalizado pelos entrevistados, encontram-se a rapidez/agilidade da aeronave e a possibilidade de atingir regiões de difícil acesso. Resultados semelhantes aos achados desse estudo demonstram que a utilização do recurso aeromédico traduz-se em assistência de saúde com suporte avançado, tempo-resposta reduzido e encaminhamento ágil do paciente a uma instituição de saúde para o tratamento definitivo (Pereira et al., 2021).

Helicópteros caracterizados como ambulância aérea, apresentam capacidade de decolagem vertical, pousam em locais não homologados (campo de futebol, estrada, entre outros), atingem regiões de difícil acesso e são capazes de reduzir significativamente o tempo de transporte do paciente (Alfes, 2020). É amplamente considerado como benéfico pois percorrem maiores distâncias em menor tempo se comparados a ambulância terrestre, podem ser empregadas técnicas de resgate e acesso diferenciado a vítima em comparação às viaturas terrestres e avião e, em grandes centros, há heliponto em muitos hospitais, facilitando o acesso.

Em contrapartida, estudos brasileiros apontam limitações no emprego de aeronaves, dentre elas: limitações às condições climáticas e noturnas, vibrações e ruídos da própria aeronave, espaço interno reduzido e custo elevado de operação, corroborando com os achados desse estudo (Pereira et al., 2021; Cardoso, Abreu, Zatta, Bastiani \& Andrade, 2017). Outra limitação refere-se as decolagens autorizadas se ocorrem antes do pôr-do-sol, visto que a maioria dos serviços de regaste aeromédico está oficializado para atendimentos diurnos, pois torna-se arriscado pouso e decolagem a noite.

Dentre as circunstâncias, ressalta-se a importância de estabilização do paciente em solo, antes do voo. Cabe salientar a importância do uso de equipamentos e materiais confiáveis, os quais são necessários para a segurança operacional e qualidade assistencial objetivando reduzir os erros e minimizar os riscos.

\section{Considerações Finais}

A realização deste estudo possibilitou compreender a realidade e percepção que os profissionais do serviço aeromédico possuem a respeito do trabalho que realizam. Demonstra que os profissionais possuem variadas interpretações a respeito do trabalho que realizam, permeados de subjetividade.

O serviço aeromédico, enquanto modalidade de atendimento de urgências e emergências, exige múltiplas competências dos profissionais envolvidos, evidenciando a importância da capacidade técnica e cognitiva para a estabilização clínica do paciente, ancorado no conhecimento sobre fisiologia de voo, segurança de voo e navegabilidade. A inter-relação de conhecimentos entre os profissionais aliado a uma resiliência física, se configuram como contribuições dos integrantes para uma assistência de qualidade.

$\mathrm{Na}$ análise das práticas cotidianas, foi possível encontrar os desafios profissionais representado por um ambiente com imprevisibilidade de acionamentos e atendimentos, permeado de responsabilidades diárias de conferência da aeronave e dos materiais e equipamentos para os atendimentos. As reflexões sobre atributos profissionais apontam para a predominância de um discurso hegemônico, com destaque para o trabalho em equipe, a comunicação e a confiança interprofissional, considerados essenciais. Além disso, evidencia-se também que os profissionais se defrontam com circunstâncias e demandas 
que requerem competências que os respaldem em situações adversas, como locais de difícil acesso e condições climáticas desfavoráveis, além de independência nas tomadas de decisões.

Por fim, salienta-se a necessidade de estudos futuros que busquem avaliar a realidade e perspectivas profissionais de serviços semelhantes, a fim mostrar essa relação de atendimento a pacientes críticos em ambientes complexos e adversos. Assim, poderão subsidiar os gestores dos serviços em estratégias com vistas a qualificá-los quando necessário, o que repercutirá diretamente na qualidade dos processos de trabalho e, por conseguinte na qualidade de assistência dos pacientes atendidos pelo serviço aeromédico.

\section{Referências}

Agência Nacional de Aviação Civil [ANAC]. (2019). Regulamento Brasileiro de Aviação Civil $n^{\circ}$ 90. Requisitos para Operações Especial de Aviação Pública. https://www.anac.gov.br/assuntos/legislacao/legislacao-1/rbha-e-rbac/rbac/rbac-90/@ @display-file/arquivo_norma/RBAC90EMD00.pdf

Alfes C. M. (2020). Improving Air Medical Transport Training: A Nurse Leader Perspective. Nurse Leader, 18(1): 63-66. https://doi.org/10.1016/j.mnl.2019.11.011

Bardin L. (2011). Análise de conteúdo (70a ed). São Paulo: Edições 70.

Blera, M. S. \& Ribas, J. L. C. (2018). Atuação do enfermeiro no transporte aeromédico. Caderno Saúde e Desenvolvimento, 13(7):5-19. https://www.cadernosuninter.com/index.php/saude-e-desenvolvimento/article/view/1033

Bonin W. L. M., Abrahão A. L., Laprovita D., Cortez E. A., Fernandes F. C., Corvino M. P .F. \& Santos N. L .P. (2016). Estratégia de educação permanente para o apoio aeromédico. Rev. Enferm. UFPE on-line, 10(6):4757-4765. 10.5205/reuol.8200-71830-3-SM.1006sup201607

Cardoso R. G., Abreu B. S. M., Zatta D., Bastiani G. \& Andrade D. (2017) Análise da Aplicação dos Conceitos de Corporate Resource Management (CRM) Nas Missões de Resgate Aeromédico no Grupamento de Radiopatrulha Aérea João Negrão. Revista Conexão SIPAER, 8(2):13-20. http://conexaosipaer.com.br/index.php/sipaer/article/view/427

Comando da Aeronáutica [COMAER]. (2012) Centro de Investigação e Prevenção de Acidentes Aeronáuticos. MCA 3-3: Manual de Prevenção do SIPAER. Brasília: CENIPA. http://www2.fab.mil.br/cenipa/index.php/legislacao/mca-manual-do-comando-da-aeronautica?download=99:mca3-3

Conselho federal de Enfermagem [COFEN]. 2021. Resolução COFEN $n^{o}$ 660/2021. Normatiza a atuação do enfermeiro na assistência direta e no gerenciamento do Atendimento Pré-Hospitalar Móvel e Inter-hospitalar em veículo aéreo.http://www.cofen.gov.br/resolucao-cofen-no-660-2021_85716.html

Costa N. M., Mello R. Z. R., Oliveira T. C. M., Parreiras M. M., Silva R. R. \& da Silva K. R. (2013). A Ótica empreendedora do enfermeiro: Capacitação e atuação de profissionais no transporte aeromédico. NBC-Periódico Científico do Núcleo de Biociências, 3(5): 39-49. http://dx.doi.org/10.15601/22381945/pcnb.v3n5p39-49

Dias C. P. \& Penna C. M. M. (2014) Air transport: the daily lives of health professionals. Rev Enferm UFPE, 8(2):3600-06. https://periodicos.ufpe.br/revistas/revistaenfermagem/article/viewFile/10099/10562

Dias C. P., Ferreira F.L. \& Carvalho V.P. (2017) A importância do trabalho em equipe no transporte aéreo de pacientes. Rev. Enferm. UFPE on-line, 11(6):2408-2014. 10.5205/reuol.10827-96111-1-ED.1106201720

Dias V. V., Camargo F. S. A., Fajer M., Bauer R. C. L., Costa M.P. \& Paiva T. M. (2010). Desenvolvimento de um instrumento de diagnóstico organizacional para os esquadrões de voo da Força Aérea Brasileira. Revista Conexão, 1(3):149-162. http://conexaosipaer.com.br/index.php/sipaer/article/view/38

Fontanella B. J., Luchesi B. M., Saidel M. G., Ricas J., Turato E. R. \& Melo D. G. (2011) Amostragem em pesquisas qualitativas: proposta de procedimentos para constatar saturação teórica. Cadernos de Saúde Pública, 27(2): 388-394. https://doi.org/10.1590/S0102-311X2011000200020

Martin J. \& Kumar K. (2020). Education Needs of Australian Flight Nurses: A Qualitative Study. Air Medical Journal, 39(3):178-182. https://doi.org/10.1016/j.amj.2020.02.001.

Ministério da Saúde. (2002). Portaria $n^{\circ}$ 2048, de 5 de novembro de 2002. Regulamento Técnico dos Sistemas Estaduais dos Serviços de Urgência e Emergência. Brasília (DF): Ministério da Saúde, Brasil. https://bvsms.saude.gov.br/bvs/saudelegis/gm/2002/prt2048_05_11_2002.html

Ministério da Saúde. (2003). Portaria $n^{o}$ 1.864, de 29 de setembro de 2003. Institui o componente pré-hospitalar móvel da Política Nacional de Atenção às Urgências: SAMU- 192. Política nacional de atenção às urgências. Diário Oficial da União, Brasília (DF). http://bvsms.saude.gov.br/bvs/publicacoes/politica_nac_urgencias.pdf

Oliveira W. A., Brandão E. C., Reis M. C. G. \& Giustina F. P. D. (2017). A importância do enfermeiro na evolução do atendimento pré-hospitalar no Brasil. Revista de Enfermagem da FACIPLAC, 2 (2): 01-12. http://revista.faciplac.edu.br/index.php/REFACI/article/view/268

Pereira A., Galdino M. J. Q., Barreto M. F. C. \& Martins J. T. (2021). Processo de trabalho no transporte aeromédico: concepções de trabalhadores. REAID, 95(34): e-21062. https://doi.org/10.31011/reaid-2021-v.95-n.34-art.1011

Raduenz S. B. P., Santos J. L. G., Lazzari D. D., Nascimento E. R. P., Nascimento K. C. \& Moreira A. R. (2020) Nurses' responsibilities in the aerospace environment. Rev Bras Enferm, 73(4): e20180777. https://doi.org/10.1590/0034-7167-2018-0777 
Research, Society and Development, v. 10, n. 12, e125101220236, 2021

(CC BY 4.0) | ISSN 2525-3409 | DOI: http://dx.doi.org/10.33448/rsd-v10i12.20236

Santa Catarina. Governo do Estado. (2010). Decreto $n^{\circ}$ 2.966, de 02 de fevereiro de 2010. Cria e Ativa O Batalhão de Operações Aéreas do Corpo de Bombeiros Militar de Santa Catarina, e Estabelece Outras Providências. Florianópolis, 2010. https://www.pilotopolicial.com.br/wpcontent/uploads/2017/01/decreto2966.pdf

Santos H. G. L, Guedes C. C. P. \& Aguiar B. G. C. (2014). Patient safety in air medical transport: a reflection on the work of nurses. Rev Acred, 4(7):21-34 Available from: https://dialnet.unirioja.es/descarga/articulo/5626590.pdf

Schweitzer G., Nascimento E. R. P., Nascimento K.C., Moreira A .R., Amante L. N. \& Malfussi L. B. H. (2017). Emergency interventions for air medical services trauma victims. Rev Bras Enferm,70(1):54-60. https://doi.org/10.1590/0034-7167-2016-0311

Tong A., Sainsbury P. \& Craig J. (2007). Consolidated criteria for reporting qualitative research (COREQ): a 32-item checklist for interviews and focus groups. International Journal for Quality in Health Care, 19(6), 349-357. https://doi.org/10.1093/intqhe/mzm042 